\title{
The natural connectivity of colored random graphs
}

\section{YILUN SHANG}

\section{ABSTRACT.}

The natural connectivity as a robustness measure of complex network has been proposed recently. It can be regarded as the average eigenvalue obtained from the graph spectrum. In this paper, we introduce an inhomogeneous random graph model, $G\left(n,\left\{c_{i}\right\},\left\{p_{i}\right\}\right)$, and investigate its natural connectivity. Binomial random graph $G\left(n, \sum_{k=1}^{m} c_{k}^{2} p_{k}\right)$ is a tight approximation for $G\left(n,\left\{c_{i}\right\},\left\{p_{i}\right\}\right)$. Simulations are performed to validate our theoretical results.

\section{UNIVERSITY OF TEXAS AT SAN ANTONIO}

INSTITUTE FOR CYBER SECURITY

SAN ANTONIO, TEXAS 78249, USA

E-mail address: shylmathehotmail.com

Received: 01.12.2010; In revised form: 30.06.2011; Accepted: 31.07.2011.

2000 Mathematics Subject Classification. 05C80, 05C40, 15A18.

Key words and phrases. Natural connectivity, Estrada index, random graph, spectral density, tunable robustness. 